\title{
Inhibition of Zinc Corrosion by Fucoidan in Natural Sea water
}

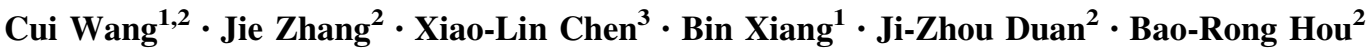

Received: 15 January 2016/Revised: 2 March 2016/Published online: 28 December 2016

(C) The Chinese Society for Metals and Springer-Verlag Berlin Heidelberg 2016

\begin{abstract}
Research on corrosion behaviour of zinc in natural sea water without and with fucoidan was carried out by potentiodynamic polarisation test and electrochemical impedance spectroscopy (EIS). The results revealed that fucoidan serves as a good inhibitor for zinc in sea water. Polarisation curves suggested that corrosion potential values shifted to the positive ones after adding inhibitor and fucoidan retards anodic reaction more. Thus, fucoidan can be acted as anodic inhibitor. EIS results showed two phenomena including a charge transfer and an adsorption film. The corrosion inhibition of fucoidan was further confirmed by the scanning electron microscope (SEM) and atomic force microscope (AFM) analysis. Langmuir's adsorption isotherm was found the appropriate adsorption model.
\end{abstract}

KEY WORDS: Zinc; Polarisation; EIS; AFM; XRD; Anodic protection

\section{Introduction}

Addition of corrosion inhibitors is a useful method for protecting metals against corrosion [1-3]. Recently, natural plant extracts have drawn considerable attention because they are non-toxic, eco-friendly, readily available and renewable [4-7]. Several promising plant extracts have already been studied in the literature for the corrosion inhibition of metals [8-10]. The effect of the extract of

Available online at http://link.springer.com/journal/40195.

Jie Zhang

zhangjie@qdio.ac.cn

$\triangle$ Bin Xiang

xiangbin@cqu.edu.cn

1 College of Chemistry and Chemical Engineering, Chongqing University, Chongqing 400044, China

2 Key Laboratory of Marine Environmental Corrosion and Biofouling, Institute of Oceanology, Chinese Academy of Sciences, Qingdao 266071, China

3 Institute of Oceanology, Chinese Academy of Sciences, Qingdao 266071, China
Aloe vera leaves on the corrosion of zinc in $2 \mathrm{M} \mathrm{HCl}$ solution was studied using a weight loss technique [9]. Inhibition efficiency of alkaloid extract from Geissospermum leaves on $\mathrm{C} 38$ steel in $1 \mathrm{M} \mathrm{HCl}$ can reach $92 \%$ with $100 \mathrm{mg} / \mathrm{L}$ at $25^{\circ} \mathrm{C}$ [10]. These compounds are rich in several heterocycles, with oxygen and nitrogen atoms incorporated in their molecular structures. Notably, numerous reports have demonstrated that most of the effective inhibitors contain $\mathrm{N}, \mathrm{S}$ and $\mathrm{O}$ atoms and $\pi$-electron systems in their structures [11-13].

Fucoidan, extracted mainly from brown seaweeds and some marine invertebrates, is a heteropolysaccharide containing a substantial number of fucose units and sulphate groups [14]. The chemical structure of fucoidan is presented in Fig. 1. It is a non-toxic and environmentally friendly substance that has been proven to have valuable pharmaceutical and biomedical activities [15-18]. However, it has never been studied for the purpose of corrosion inhibition, and it will act as a promising green inhibitor.

This study aimed to examine the inhibitory effect of fucoidan on zinc corrosion in natural sea water and gain deeper insight into the mechanisms underlying inhibition. The protective effect of the inhibitor was investigated by 


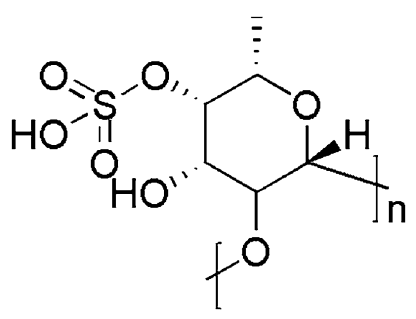

Fig. 1 Chemical structure of fucoidan

potentiodynamic polarisation and electrochemical impedance spectroscopy (EIS). Additionally, the surface properties were evaluated using scanning electron microscopy (SEM) and atomic force microscopy (AFM).

\section{Materials and Methods}

\subsection{Preparation of the Samples}

Corrosion experiments were performed on zinc specimens. Sea water was obtained from Huiquan Bay in Qingdao and filtered before use. Table 1 lists the parameters of sea water. Fucoidan $\left(\mathrm{C}_{6} \mathrm{H}_{10} \mathrm{O}_{7} \mathrm{~S}\right)_{n}$ was provided by another research group of Chinese Academy of Sciences, and the extraction method is described in detail in the literature [19]. Figure 1 is the molecular structure of fucoidan. For electrochemical tests, the working electrode was cut from zinc specimen and protected by epoxy resin, leaving only $1 \mathrm{~cm}^{2}$ surface area exposed to the testing solutions. Prior to use, samples were wet ground using emery paper of different grades (800-2000 grain size), rinsed with distilled water, degreased with ethanol and dried under room temperature before use.

\subsection{Electrochemical Measurements}

The electrochemical experiments were performed using Solartron 1287 and Solartron 1260, and the results were analysed with ZSimpWin software. A conventional threeelectrode glass cell was used for the experiments. Pure zinc specimen was used as the working electrode. A platinum wire was used as the counter electrode, and a saturated calomel electrode was used as the reference electrode. The reference electrode was connected via a Luggin capillary.

Table 1 Parameters of sea water

\begin{tabular}{llllll}
\hline & Spcond & Salinity & DO nonc $(\mathrm{mg} / \mathrm{L})$ & $\mathrm{pH}$ & ORP $(\mathrm{mV})$ \\
\hline $\begin{array}{l}\text { Sea } \\
\text { water }\end{array}$ & 49.99 & 32.79 & 7.46 & 8.33 & 32.8 \\
\hline
\end{tabular}

DO dissolved oxygen, ORP oxidation reduction potential
All experiments were conducted in natural sea water with different fucoidan concentrations at $25 \pm 1{ }^{\circ} \mathrm{C}$.

The working electrode was immersed in the testing solution for $30 \mathrm{~min}$ to reach a quasi-stationary value of the open circuit potential prior to the measurements. Impedance measurements were made at the corrosion potential $\left(E_{\text {corr }}\right)$ over a frequency range of $100 \mathrm{kHz}$ to $10 \mathrm{mHz}$, with an AC voltage amplitude of $10 \mathrm{mV}$. The data were interpreted with ZSimpWin software. The potentiodynamic polarisation study was conducted from the cathodic potential of $-250 \mathrm{mV}$ to the anodic potential of $+250 \mathrm{mV}$ with respect to the corrosion potential at a sweep rate of $1 \mathrm{mV} / \mathrm{s}$. Each experiment was carried out three times to estimate reproducibility and good repeatability was achieved.

\subsection{Surface Characterisation}

The morphology of the zinc surface was analysed by SEM (SN3400) and AFM after exposure to sea water in the absence and presence of fucoidan $(100 \mathrm{mg} / \mathrm{L})$ at $298 \mathrm{~K}$ for a designated period.

\section{Results and Discussion}

\subsection{Electrochemical Measurements}

\subsubsection{Potentiodynamic Polarisation Measurements}

The potentiodynamic polarisation curves of zinc in natural sea water with fucoidan at different concentrations are shown in Fig. 2.

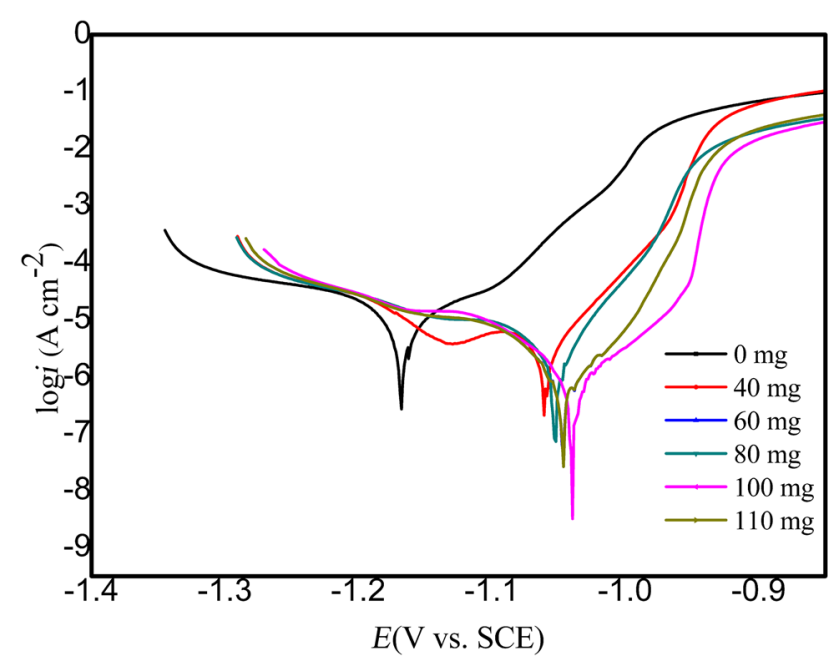

Fig. 2 Polarisation curves for zinc in natural sea water with fucoidan at different concentrations 
The anodic and cathodic processes of zinc corrosion in the solution can be described as follows [20, 21]:

Anodic:

$\mathrm{Zn} \rightarrow \mathrm{Zn}^{2+}+2 \mathrm{e}^{-}$.

Cathodic:

$\mathrm{O}_{2}+2 \mathrm{H}_{2} \mathrm{O}+4 \mathrm{e}^{-} \rightarrow 4 \mathrm{OH}^{-}$.

Along with the corrosion reactions, cathodic alkalinity increased because of the release of $\mathrm{OH}^{-}$at the cathodic site. Thus, $\mathrm{Zn}(\mathrm{OH})_{2}$ was deposited on the zinc electrode surface. With the formation of the corrosion product film, the corrosion should be retarded. However, the result is unsatisfactory. Actually, the film became porous because of the reaction among $\mathrm{Cl}^{-}, \mathrm{HCO}_{3}^{2-}$ and $\mathrm{Zn}(\mathrm{OH})_{2}$, which generated zinc hydroxide chloride and zinc hydroxide carbonate $[22,23]$. To confirm the composition of the film, $\mathrm{X}$-ray diffraction (XRD) was used, and the results are displayed in Fig. 3. The JCPDS database indicated that the diffraction lines registered at $2 \theta=28.63$ or 33.57 confirmed the presence of $\mathrm{Zn}_{5}(\mathrm{OH})_{8} \mathrm{Cl}_{2}$. The diffraction lines registered at approximately 39.13 were due to $\mathrm{Zn}_{5}(\mathrm{OH})_{6}\left(\mathrm{CO}_{3}\right)_{2} \cdot \mathrm{H}_{2} \mathrm{O}$, but only a small quantity was generated on the electrode surface. All the reactions promoted pitting corrosion on the zinc surface.

As shown in Fig. 2, the corrosion potential values shifted to positive values, and the corrosion current density decreased slightly because of the addition of fucoidan. Therefore, fucoidan effectively prevented zinc from corrosion in sea water. As documented in the literature, one inhibitor can been seen as a cathodic or anodic type if the displacement in $E_{\text {corr }}$ (inhibitor) is $>85 \mathrm{mV}$ with respect to $E_{\text {corr }}$ (blank) $[24,25]$. Therefore, fucoidan can be acted as an anodic inhibitor because the anodic region was affected more than the cathodic region. A peak was observed at $-1.14 \mathrm{~V}$ on the cathodic polarisation curve, except on the blank one. This peak was caused by the presence of zinc oxide [8]. To confirm this result, we deposited at the

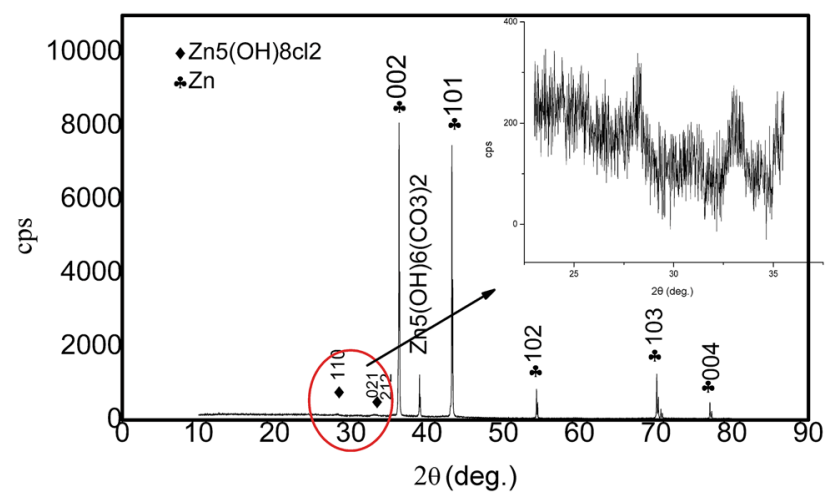

Fig. 3 XRD pattern of corrosion products on electrode surface after immersed in natural sea water for 7 days potential of $-1.14 \mathrm{~V}$ for 2 days, and Fig. 4 shows XRD results. The main product on the electrode surface was zinc oxide.

Given that the zinc electrode immersed in sea water did not exhibit Tafel behaviour, calculations with liner extrapolation are not possible. However, the inhibitor efficiency $(\eta)$ was determined by calculating $R_{\mathrm{P}}$ using Eq. (3). The $R_{\mathrm{P}}$ value was obtained using the linear $I-E$ plots in the potential range of $\pm 20 \mathrm{mV}$ from the corrosion potential.

$\eta(\%)=\frac{R_{\mathrm{p}}-R_{\mathrm{p}}^{0}}{R_{\mathrm{p}}} \times 100 \%$,

where $R_{\mathrm{P}}^{0}$ and $R_{\mathrm{P}}$ are the polarisation resistance values of the zinc electrode in sea water without and with fucoidan, respectively.

Table 2 suggests that the polarisation resistance increased and inhibition efficiency increased with increasing inhibitor concentration before it reached $100 \mathrm{mg} / \mathrm{L}$. Furthermore, the inhibition efficiency does not grow when the inhibitor concentration was $120 \mathrm{mg} / \mathrm{L}$.

\subsubsection{EIS Measurements}

The Nyquist and Bode plots of the zinc electrode at different fucoidan concentrations in sea water are shown in Fig. 5. The shape of the curves for impedance diagrams was highly similar to tests, which suggested no difference for the corrosion mechanism as a result of fucoidan addition. The Nyquist plots obtained for the zinc electrode in test solutions exhibited two capacitive loops. For the blank, a depressed semicircle was observed in the high frequency region, which could be attributed to the dispersion effect; moreover, the straight line in the low frequency region

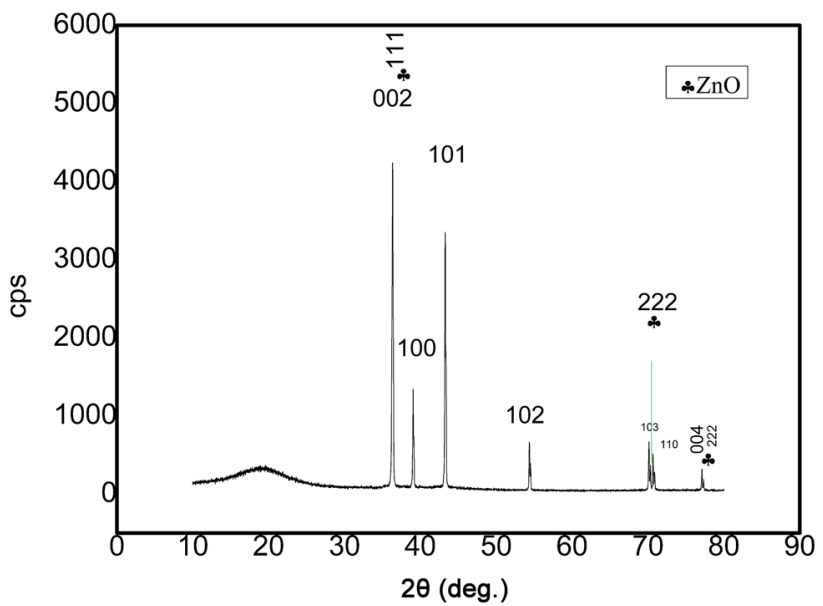

Fig. 4 XRD pattern on electrode surface after deposited at the potential of $-1.14 \mathrm{~V}$ for two days 
Table 2 Potentiodynamic polarisation parameter for zinc in natural sea water with various concentrations of fucoidan at $25^{\circ} \mathrm{C}$

\begin{tabular}{|c|c|c|c|}
\hline Concentrations & $E_{\text {corr }}$ versus SCE $(\mathrm{V})$ & $R_{\mathrm{p}}\left(\Omega \mathrm{cm}^{2}\right)$ & $\eta(\%)$ \\
\hline Blank & -1.1661 & 826.65 & \\
\hline $40 \mathrm{mg} \mathrm{L}^{-1}$ & -1.0609 & 3206.7 & 74.22 \\
\hline $60 \mathrm{mg} \mathrm{L}^{-1}$ & -1.053 & 4362.8 & 81.05 \\
\hline $80 \mathrm{mg} \mathrm{L}^{-1}$ & -1.0507 & 6949.1 & 88.1 \\
\hline $100 \mathrm{mg} \mathrm{L}^{-1}$ & -1.0452 & 11,711 & 92.35 \\
\hline $120 \mathrm{mg} \mathrm{L}^{-1}$ & -1.0385 & 10,806 & 92.94 \\
\hline
\end{tabular}

indicated a diffusion-controlled process. By contrast, the impedance diagrams in both shape and size showed notable changes for the zinc electrode exposed to different fucoidan concentrations. After adding fucoidan in sea water, the diameter of the capacitive loop in the high frequency region increased, which suggested that chargetransfer resistance increased.

Therefore, the equivalent circuit shown in Fig. 6 was proposed for the corrosion system to fit the representative data. $R_{\mathrm{S}}$ represents the electrolyte resistance. $R_{1}$ and $R_{2}$ are the charge-transfer resistance and film resistance of the corrosion products, respectively. $Q_{1}$ and $Q_{2}$ represent the constant phase elements (CPE), where $Q_{1}$ is composed of the double-layer capacitance $C_{\mathrm{dl}}$ and the deviation parameter $\alpha_{1}$ and $Q_{2}$ is composed of the membrane capacitance $C_{\mathrm{f}}$ and the deviation parameter $\alpha_{2}$. The CPE is substitute for the capacitive element to give a more accurate fit and defined by $Q$ and $\alpha$ which can been described by Eq. (4) $[26,27]$ :

$Z_{\mathrm{CEP}}=Q^{-1} \times(i w)^{-\alpha}$,

where $Q$ is the CPE constant, $\omega$ is the angular frequency, $i$ is the imaginary number and $\alpha$ is CPE exponent which is used as a gauge of heterogeneity or roughness of the surface.

The fitted equivalent circuit parameters of zinc are presented in Table 2. The inhibition efficiency calculated by Eq. (5) is listed in the same table.

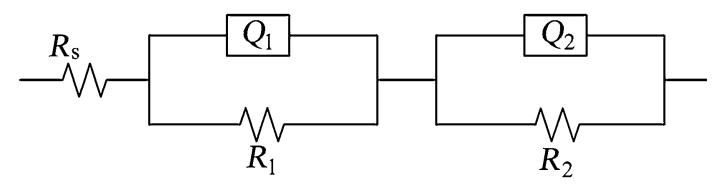

Fig. 6 Equivalent circuit used to fit the EIS experimental data

$\eta(\%)=\frac{R_{\mathrm{t}}-R_{\mathrm{t}}^{0}}{R_{\mathrm{t}}} \times 100 \%$,

where $R_{\mathrm{t}}$ is the total resistance in the present and absence of extract. As shown in Table $3, R_{\mathrm{s}}$ remained almost unchanged before and after the addition of the inhibitor. With increasing inhibitor concentration, $R_{1}$ and $R_{2}$ increased, and therefore, the total resistance $R_{\mathrm{t}}\left(R_{\mathrm{t}}=\right.$ $R_{1}+R_{2}$ ) increased with the increase in the inhibitor concentration and then peaked at $100 \mathrm{mg} \mathrm{L}^{-1}$, which resulted in an increase in inhibition efficiency. Moreover, the results (\%) obtained from EIS measurement and polarisation test were in agreement with each other. The increase in $R_{1}$ indicated that the inhibitor molecules replaced the water molecules and other ions and were adsorbed on the electrode, forming a protective layer. Consequently, the active sites for corrosion reaction decreased and resistance increased. Meanwhile, $R_{2}$ increased because of the corrosion products, which covered the zinc surface and formed a layer preventing the reactions. Upon comparing $\alpha_{1}$ and $\alpha_{2}$ values with and without an inhibitor, the results indicated that surface heterogeneity of zinc decreased because of the adsorption of fucoidan and corrosion products.

\subsection{Surface Morphological Analysis}

\subsubsection{SEM Study}

The surface morphologies of electrodes were observed by SEM. Figure 7a shows the original zinc surface before test. The surface was smooth with only some nicks. As shown in Fig. $7 b$, the sample surface in sea water without fucoidan after 7 days was damaged during the test. Obviously, the process resulted in pitting, and corrosion products were
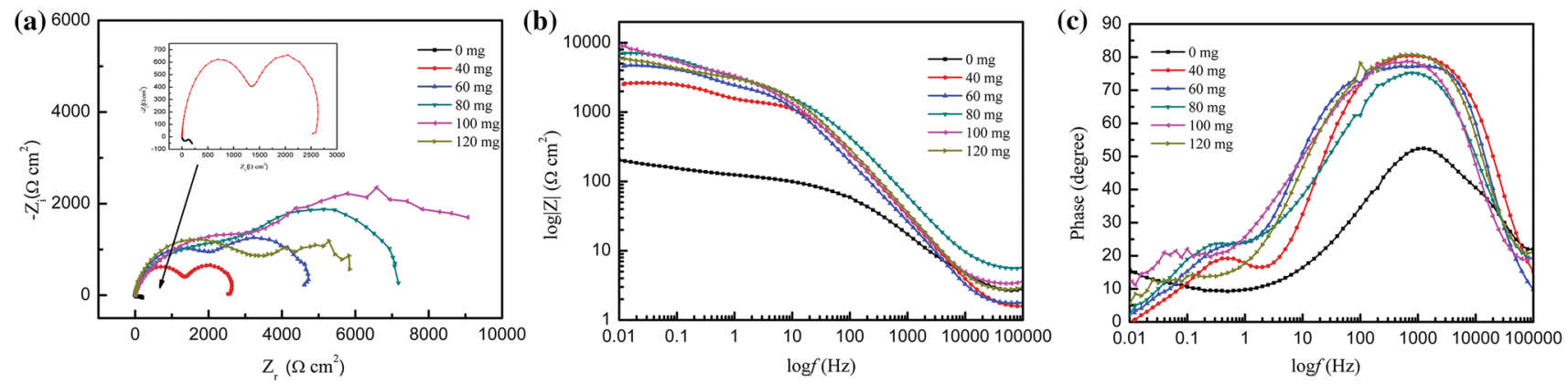

Fig. 5 Nyquist a, Bode b, c plots of zinc electrode at different concentrations of fucoidan in natural sea water 
Table 3 Impedance parameter for zinc in natural sea water in the absence and presence of different concentrations of fucoidan at $298 \mathrm{~K}$

\begin{tabular}{|c|c|c|c|c|c|c|c|c|}
\hline Parameters & $R_{\mathrm{s}}\left(\Omega \mathrm{cm}^{2}\right)$ & $Q_{1} 10^{-4}\left(\mathrm{~S}^{\mathrm{n}} / \mathrm{cm}^{2}\right)$ & $n_{1}$ & $R_{1}\left(\Omega \mathrm{cm}^{2}\right)$ & $Q_{2} 10^{-4}\left(\mathrm{~S}^{\mathrm{n}} / \mathrm{cm}^{2}\right)$ & $n_{2}$ & $R_{2}\left(\Omega \mathrm{cm}^{2}\right)$ & $\eta(\%)$ \\
\hline Blank & 1.70 & 1.19 & 0.724 & 97.03 & 160.5 & 0.380 & 290.3 & \\
\hline $40 \mathrm{mg} \mathrm{L}^{-1}$ & 1.396 & 4.26 & 0.8778 & 1413 & 0.094 & 0.9350 & 1296 & 82.75 \\
\hline $60 \mathrm{mg} \mathrm{L}^{-1}$ & 1.533 & 2.58 & 0.8614 & 2882 & 0.16 & 0.9082 & 1943 & 90.31 \\
\hline $80 \mathrm{mg} \mathrm{L}^{-1}$ & 4.675 & 1.46 & 0.7455 & 5519 & 0.088 & 0.8846 & 1845 & 93.90 \\
\hline $100 \mathrm{mg} \mathrm{L}^{-1}$ & 3.221 & 2.57 & 0.7280 & 7039 & 0.18 & 0.8153 & 2339 & 95.02 \\
\hline $120 \mathrm{mg} \mathrm{L}^{-1}$ & 2.36 & 4.592 & 0.7809 & 3229 & 0.10 & 0.9202 & 2700 & 92.12 \\
\hline
\end{tabular}
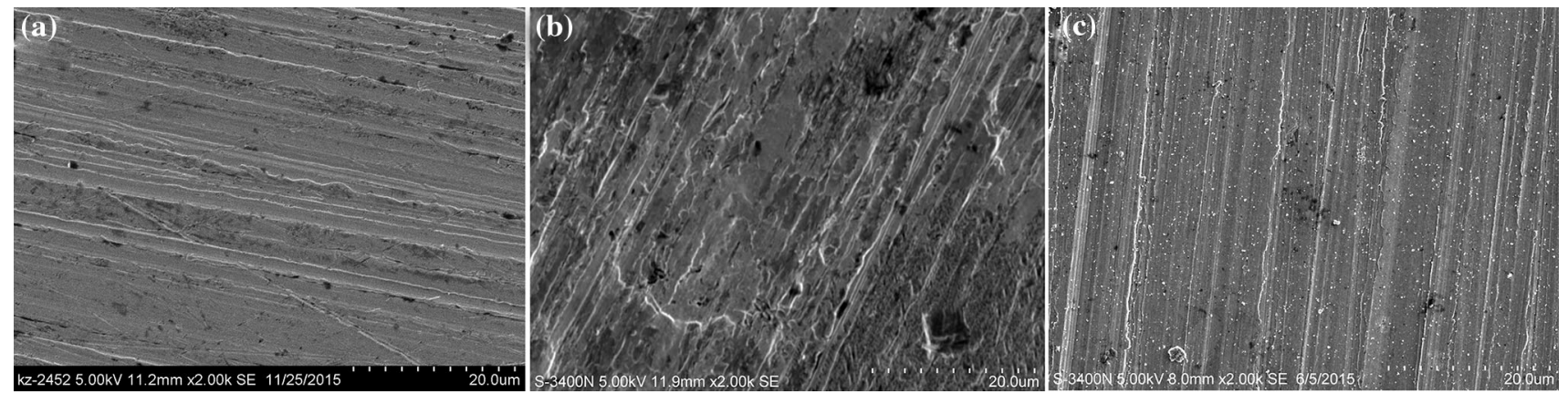

Fig. 7 SEM micrographs of freshly polished zinc sample a; exposed zinc in natural sea water for 7 days $\mathbf{b}$; exposed zinc in natural sea water containing $100 \mathrm{mg} \mathrm{L}^{-1}$ for 7 days at $298 \mathrm{~K} \mathrm{c}$

deposited on the porous electrode surface. By contrast, less damage was observed for the electrode in sea water after adding fucoidan. Only minimal pitting appeared, and a few corrosion products generated on the zinc surface. This phenomenon suggested that fucoidan was a good inhibitor to prevent zinc corrosion.

\subsubsection{AFM Surface Morphology}

The surface topography of zinc specimens immersed in different test solutions for 7 days was studied by AFM. Figure $8 \mathrm{a}-\mathrm{c}$ illustrates the freshly polished electrode, electrode treated with electrolytes without and with inhibitor. Figure 8a shows that the electrode surface was mostly uniform with some minor shallow scratches.
Comparison between Fig. 8b and c, the surface with inhibitor was flat and had a small number of pothole shapes. These results were in agreement with the findings of SEM analysis.

\subsection{Corrosion Inhibition Mechanism}

The polarisation and impedance measurements indicated that fucoidan can be acted as a good inhibitor for zinc in natural sea water because it can be adsorpted on the electrode surface. In general, the adsorption of inhibitors depends on the chemical structure of the inhibitor and on the nature of the metal $[28,29]$. The corrosion product is primitively supposed to consist of $\mathrm{ZnO}$ and/or $\mathrm{Zn}(\mathrm{OH})_{2}$. However, adsorbed chloride ions, one type of aggressive (a)

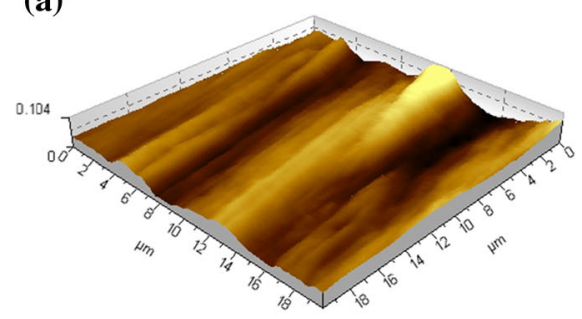

(b)

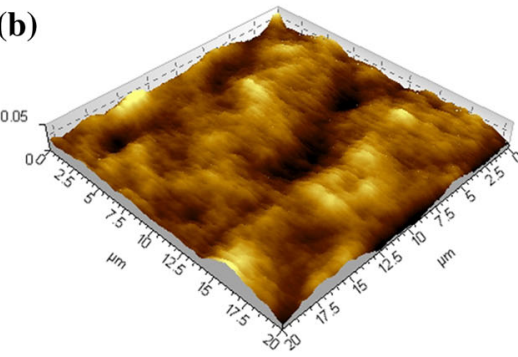

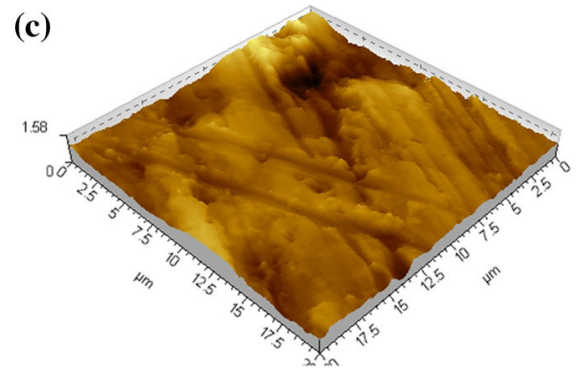

Fig. 8 AFM images of freshly polished zinc sample a; immersed in natural sea water without inhibitor $\mathbf{b}$; immersed in natural sea water with various concentrations of inhibitor $\mathbf{c}$ 


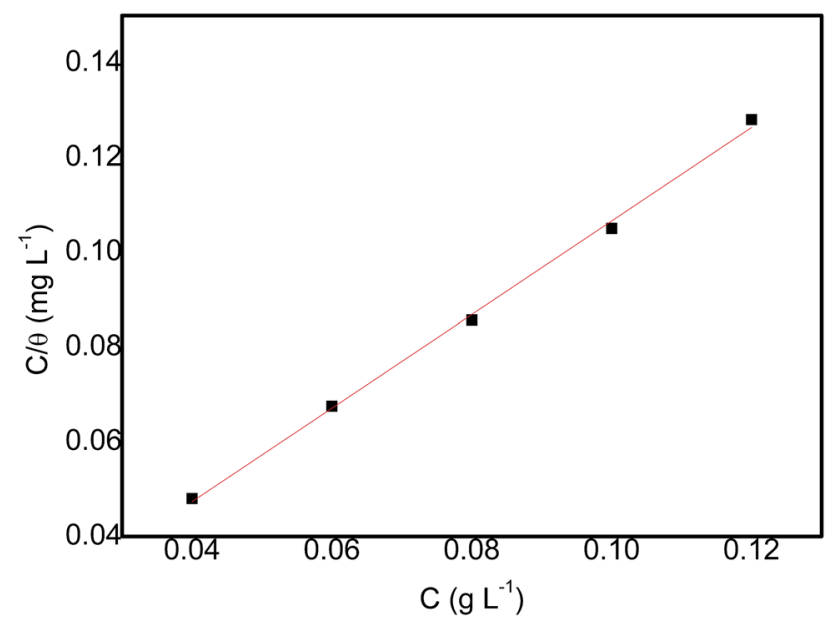

Fig. 9 Langmuir adsorption plot for zinc in natural sea water containing different concentrations of fucoidan

halide anion, penetrated the passive film on the zinc surface and incorporated in the film as a porous composite, altering its physical and electrical properties [22]. Fucoidan (Fig. 1) has a number of sulphur and oxygen atoms and a large number of heterocyclic rings. Thus, fucoidan molecules should be electrostatically adsorbed on the steel surface. The adsorption of inhibitors may mainly involve the following two mechanisms. One is the competitive adsorption between fucoidan and aggressive chloride ion on the zinc electrode. According to the molecular structure, hydrophilic groups (sulphate radical) and hydrophobic heterocyclic groups are present. The former provides a strong adsorbing force between inhibitor and the electrode surface, whereas the latter expels chloride ions, even some water molecules, from the electrode surface. Consequently, an adsorbed fucoidan layer blocks the active surface sites on the electrode surface for anodic dissolution. Another mechanism is the competition between the sulphate radical group of fucoidan and chloride ion to form a complex with zinc ions. The polarisation test suggested that zinc-chloride complexes and subsequent $\mathrm{Zn}_{5}(\mathrm{OH})_{8} \mathrm{Cl}_{2}$ formation will accelerate corrosion, especially localised corrosion. By contrast, the localised corrosion was inhibited in the fucoidan-added solutions, as observed on the surface.

\subsection{Adsorption Isotherm Behaviour}

To understand the mechanism of inhibition, Langmuir, Temkin and Frumkin adsorption isotherms were applied to explain the adsorption behaviour of the inhibitor molecules. These adsorption isotherms were obtained according to the following equations $[30,31]$ :
Langmuir:

$\frac{C_{\mathrm{inh}}}{\theta}=\frac{1}{K}+C_{\mathrm{inh}}$.

Temkin:

$\exp (-2 \alpha \theta)=b C_{\text {inh }}$.

Frumkin:

$$
\left(\frac{\theta}{1-\theta}\right) \exp (-2 \alpha \theta)=b C_{\mathrm{inh}} \text {, }
$$

where $\theta$ is the surface coverage of the metal surface, $C_{\mathrm{inh}}$ is the concentration of inhibitor, $K$ is the adsorptiondesorption equilibrium constant, $a$ is the adsorbate interaction parameter and $b$ is the equilibrium constant for fucoidan. The surface coverage degree $(\theta)$, which is in accordance with the inhibitor concentration, was calculated using Eq. (9) [32-34].

$\theta=\frac{R_{\mathrm{t}}-R_{\mathrm{t}}^{0}}{R_{\mathrm{t}}}$.

After several attempts, the experimental data attained from the polarisation curves could be fitted by the Langmuir adsorption isotherm. The respective plot is presented in Fig. 9, which shows a linear relationship between $C_{\text {ihn }} / \theta$ and $C_{\text {inh }}$ with a correlation coefficient of 0.99 . This result suggested that the inhibitor obeyed the Langmuir adsorption isotherm in natural sea water.

\section{Conclusions}

1. Fucoidan behaved as a good inhibitor that protected zinc from corrosion in natural sea water. With the increase in the fucoidan concentration, the inhibition efficiency increased and peaked at $100 \mathrm{mg} / \mathrm{L}$.

2. The polarisation test demonstrated that fucoidan effectively inhibited the anodic reaction, so fucoidan was considered as anodic inhibitor.

3. Two capacitive loops in the EIS measurement were present. One was for the charge transfer, and the other was attributed to the passive layer.

4. The SEM and AFM results revealed that fucoidan could effectively retard the corrosion reaction of zinc in natural sea water because of the adsorption of fucoidan on the surface of the zinc electrode.

5. The adsorption behaviour of fucoidan followed Langmuir adsorption isotherm theory.

Acknowledgements This work was supported by the National Natural Science Foundation of China (Nos. 41376003 and 41006054) and the National Basic Research Program of China (No. 2014CB643304). 


\section{References}

[1] B. Qian, B. Hou, M. Zheng, Corros. Sci. 72, 1 (2013)

[2] H. Amar, T. Braisaz, D. Villemin, B. Moreau, Mater. Chem. Phys. 110, 1 (2008)

[3] Y. Ren, Y. Luo, K. Zhang, G. Zhu, X. Tan, Corros. Sci. 50, 3147 (2008)

[4] S. Deng, X. Li, Corros. Sci. 64, 253 (2012)

[5] P. Mourya, S. Banerjee, M.M. Singh, Corros. Sci. 85, 352 (2014)

[6] A. Singh, Y. Lin, E.E. Ebenso, W. Liu, J. Pan, B. Huang, J. Ind. Eng. Chem. 24, 219 (2015)

[7] O.K. Abiola, J.O.E. Otaigbe, O.J. Kio, Corros. Sci. 51, 1879 (2009)

[8] F. Suedile, F. Robert, C. Roos, M. Lebrini, Electrochim. Acta 133, 631 (2014)

[9] O.K. Abiola, A.O. James, Corros. Sci. 52, 661 (2010)

[10] M. Faustin, A. Maciuk, P. Salvin, C. Roos, M. Lebrini, Corros. Sci. 92, 287 (2015)

[11] I. Ahamad, R. Prasad, M.A. Quraishi, Corros. Sci. 52, 933 (2010)

[12] H.M. Abd, El-Lateef. Corros. Sci. 92, 104 (2015)

[13] L. Fragoza-Mar, O. Olivares-Xometl, M.A. Domínguez-Aguilar, E.A. Flores, P. Arellanes-Lozada, F. Jiménez-Cruz, Corros. Sci. 61, 171 (2012)

[14] S. Lee, C. Ko, Y. Jee, Y. Jeong, M. Kim, J. Kim, Y. Jeon, Carbohyd. Polym. 92, 84 (2013)

[15] S.J. Lim, W.M. Wan Aida, M.Y. Maskat, S. Mamot, J. Ropien, D.M. Mohd, Food Hydrocolloids 42, 280 (2014)

[16] E. Sinurat, P.D. Rosmawaty, Procedia Environ. Sci. 23, 407 (2015)
[17] S. Lim, J. Choi, H. Park, Radiat. Phys. Chem. 109, 23 (2015)

[18] M.I. Bilan, A.A. Grachev, N.E. Ustuzhanina, A.S. Shashkov, N.E. Nifantiev, A.I. Usov, Carbohydr. Res. 337, 719 (2002)

[19] X. Cheng, R. Xing, H. Yu, S. Liu, P. Li, Desalin. Water Treat. 40, 204 (2012)

[20] K. Aramaki, Corros. Sci. 43, 591 (2001)

[21] H.J. Flitt, D.P. Schweinsberg, Corros. Sci. 52, 1905 (2010)

[22] M. Mouanga, P. Berçot, J.Y. Rauch, Corros. Sci. 52, 3984 (2010)

[23] M. Mouanga, P. Berçot, Corros. Sci. 52, 3993 (2010)

[24] T. Ramde, S. Rossi, C. Zanella, Appl. Surf. Sci. 307, 209 (2014)

[25] H. Ashassi-Sorkhabi, M.R. Majidi, K. Seyyedi, Appl. Surf. Sci. 225, 176 (2004)

[26] J.R. Macdonald, J. Electroanal. Chem. Interfacial Electrochem. 223, 25 (1987)

[27] Z. Stoynov, Electrochim. Acta 35, 1493 (1990)

[28] D. Wang, B. Xiang, Y. Liang, S. Song, C. Liu, Corros. Sci. 85, 77 (2014)

[29] A. Yurt, B. Duran, H. Dal, Arab. J. Chem. 7, 732 (2014)

[30] I.B. Obot, S.A. Umoren, Z.M. Gasem, R. Suleiman, B.E. Ali, J. Ind. Eng. Chem. 21, 1328 (2015)

[31] I.B. Obot, N.O. Obi-Egbedi, S.A. Umoren, Corros. Sci. 51, 1868 (2009)

[32] M. Bobina, A. Kellenberger, J. Millet, C. Muntean, N. Vaszilcsin, Corros. Sci. 69, 389 (2013)

[33] S. Pournazari, M.H. Moayed, M. Rahimizadeh, Corros. Sci. 71, 20 (2013)

[34] L. Li, Q. Qu, W. Bai, F. Yang, Y. Chen, S. Zhang, Z. Ding, Corros. Sci. 59, 249 (2012) 